\title{
TÉCNICOS EM FARMÁCIA: TRAJETÓRIAS FORMATIVAS DE EGRESSOS DO CURSO TÉCNICO DE NÍVEL MÉDIO EM FARMÁCIA
}

\author{
SEBASTIÃO GONÇALVES DE BARROS NETO'; ${ }^{1}$ ALEXANDRE JACOB ${ }^{2}$
}

\begin{abstract}
${ }^{1}$ Farmacêutico, Mestre, Doutorando em Distúrbios do Desenvolvimento pela Universidade Presbiteriana Mackenzie (UPM), Especialista em Educação Profissional e Tecnológica pelo Instituto Federal do Espírito Santo (IFES). E-mail: sebastiaogbarros@outlook.com.

${ }^{2}$ Advogado, Mestre, Docente do Curso de pós-graduação lato sensu em Educação Profissional e Tecnológica do Instituto Federal do Espírito Santo (IFES). E-mail: alexandre.jacob10@gmail.com.
\end{abstract}

\section{RESUMO}

A pesquisa propõe-se analisar as trajetórias formativas dos Técnicos em Farmácia, egressos dos Cursos Técnicos de Nível Médio em Farmácia, pois, ao passo que se reconhece a Farmácia como promotora de saúde, entende-se que seus recursos humanos devem possuir educação formal específica, regulamentação ocupacional e profissional, registro e exercício profissional fiscalizado por órgão competente. Para concretizar a investigação, utilizou-se o estudo de campo descritivo de desenho - natureza qualitativa online (por intermédio da internet) -, com entrevistas assíncronas, realizadas por questionário semiestruturado enviado por e-mail para obtenção das histórias de vida (ou biografias). As narrativas das histórias formativas de vida dos profissionais de nível Técnico em Farmácia possibilitaram descrever, conhecer e problematizar o contexto da formação Técnica em Farmácia no Brasil e propor novos caminhos para a área Técnica em Farmácia Brasileira, em especial para a Educação Profissional e Tecnológica em Saúde.

Palavras-chave: Técnico em Farmácia; Educação Profissional em Saúde; Políticas Públicas; Assistência Farmacêutica; Método (auto) biográfico.

\section{PHARMACY TECHNICIANS: FORMATIVE TRAJECTORIES OF GRADUATES OF TECHNICAL COURSES OF VOCATIONAL SCHOOLS IN PHARMACY}

\begin{abstract}
The research proposes the analysis of the formative trajectories of pharmacy technicians, graduates of technical courses of vocational schooling in Pharmacy. While recognizing this area as a promoter of health, it is understood that these professionals must have specific formal education, occupational and professional regulation, registration and professional exercise supervised by a competent body. To carry out the
\end{abstract}


research, a descriptive qualitative field study was performed online (through the internet), with asynchronous interviews, carried out by a semi-structured questionnaire sent by email to obtain life histories (or autobiographies). These narratives of life histories of technical level professionals in Pharmacy allowed us to describe, know and problematize the context of their formation in Brazil and to propose new paths for the technical area in Brazilian Pharmacy, especially for professional and technological education in healthcare.

Keywords: Pharmacy Technician; Professional Education in Health; Public Policies; Pharmaceutical Assistance; Autobiographical Method.

\section{INTRODUÇÃO}

Desde sua instituição, sobretudo no último decênio, a Rede Federal de Educação Profissional, Científica e Tecnológica tem se expandido por intermédio da criação de novos Institutos Federais de Educação, Ciência e Tecnologia (IF), tendência também observada na esfera da educação privada; por conseguinte, novos cursos técnicos de nível médio e superior, bem como os de pós-graduação lato e stricto sensu foram criados. Em meio a esse contexto de expansão, originaram-se cursos que diplomam e conferem o grau de Técnico de Nível Médio em Farmácia em diferentes instituições públicas e privadas de ensino, conjuntura que, possivelmente, a longo prazo, colocará um fim na ausência de indivíduos atuando sem a devida qualificação requerida teoricamente pelo segmento farmacêutico, tornando obsoleto o profissional sem educação formal - auxiliar de Farmácia, balconista e o "prático". No Brasil, diferentemente de outros países, grande parte dos serviços e das atividades de saúde não privativas do Farmacêutico são realizados por leigos: auxiliares de farmácia, balconistas e "práticos" (NAVES; MERCHAN-HAMANN; SILVER, 2005; BEZZEGH; GOLDENBERG, 2011; CORRER; OTUKI, 2013).

O Ministério da Educação, por meio do Catálogo Nacional de Cursos Técnicos, reconheceu o Curso de Nível Médio em Técnico em Farmácia. No entanto, a Lei $\mathrm{n}^{\circ}$ 3.820, de 11 de novembro de 1960, e a Lei $\mathrm{n}^{\circ}$ 5.991, de 17 de dezembro de 1973, não preveem a incorporação desse profissional - inscrição de quadros separados com a denominação “Técnico em Farmácia” nos Conselhos Regionais de Farmácia. Portanto, os concluintes dos cursos de formação e habilitação Técnica em Farmácia acabam por atuar no mercado sob a supervisão do Farmacêutico sem o registro (BRASIL, 1960; 
PEREIRA, 2009; CORRAL; SOUZA; NEGRÃO, 2009; CORRER; PONTAROLO; RIBEIRO, 2013).

A inexistência de uma legislação específica que regulamente e exija a formação técnica em Farmácia para atuar no segmento do mercado farmacêutico repercute de modo negativo na oferta e na demanda de cursos profissionalizantes de Técnico em Farmácia. Portanto, poucos possuem formação compatível com o cargo ou função (por não existir uma exigência); em geral, possuem baixa escolaridade, pouca ou nenhuma formação específica na área (CORRER; PONTAROLO; RIBEIRO, 2013, BARROS NETO; CYSMEIROS; BORGES, 2018).

A atenção primaria é a principal área de trabalho Farmacêutico e Técnico em Farmácia no Brasil (CORRER; OTUKI, 2013). Tanto no serviço privado quanto no serviço público, suas atividades correspondem às ações do processo de trabalho dos diversos segmentos da área farmacêutica. O conjunto dessas atividades, no plano institucional ou na sociedade, são identificados como serviços. Os serviços técnicogerenciais, que incluem a programação, a solicitação, o armazenamento e o descarte de produtos farmacêuticos, são de natureza técnica específica, da mesma forma que os serviços técnicos assistenciais farmacêuticos (dispensação, orientação, consulta, revisão da farmacoterapia, conciliação terapêutica, seguimento farmacoterapêutico, ações de educação em saúde e suporte técnico para a equipe de saúde) (BRASIL, 2009b; CONSELHO FEDERAL DE FARMÁCIA, 2013).

Na Prática Farmacêutica e Técnica em farmácia comunitária, as atividades se dividem entre gerenciais e administrativas, assistenciais e clínicas. Nas atividades assistenciais e clínicas, os Técnicos em Farmácia auxiliam o Farmacêutico na documentação do Cuidado Farmacêutico, cooperando para a oferta do gerenciamento integral da farmacoterapia prescrita (MELO et al., 2017).

As instituições formadoras, ao educar para o exercício farmacêutico, conferindo o grau de bacharel em Farmácia, além de subsídios teóricos, técnicos e intelectuais, objetivam também a formação de indivíduos emancipados, críticos e reflexivos. Portanto, tem se buscado pautar o ensino no princípio da integralidade omnilateralidade -, objetivando a formação humana de maneira oposta à formação unilateral que advém do trabalho alienado, produto das inter-relações entre a divisão do trabalho, a reificação e as relações burguesas. Destarte, deve ser considerada a 
totalidade, compreendendo de modo integral as relações sociais e políticas. Consequentemente, há um esforço de ofertar uma proposta de educação ampliada, transformadora, crítica e libertadora que, entre outras coisas, conceba o homem como ser integrado às forças sociais e, de forma alguma, como subserviente às forças produtivas. Dessa forma, os profissionais farmacêuticos formados com essa visão deveriam ter um posicionamento diferente no que se refere à qualificação e ao reconhecimento profissional dos Técnicos em Farmácia, uma vez que, ao nos debruçarmos sobre a literatura disponível, evidenciamos a complexidade do trabalho entre Técnicos em Farmácia e Farmacêuticos, visto que se encontram em um campo enredado de interesses, poder, disputas e resistências por parte dos Farmacêuticos e dos Conselhos de Farmácia (BARROS NETO; CYSNEIROS; BORGES, 2018).

Os Cursos Técnicos de Nível Médio em Farmácia estão fundamentados nos princípios norteadores da EPT. Desse modo, também visam a oferta de uma educação que forme na perspectiva da omnilateralidade, ao desenvolver habilidades $\mathrm{e}$ competências humanas; ao preparar cada indivíduo para o exercício pleno de suas funções e de conhecimentos adquiridos com discernimento e propositividade, para compreender e contextualizar a educação e o trabalho como fruto de uma produção social (MERHY, 2002; BARROS NETO, 2017) e para que sejam protagonistas de uma cogestão, no que se refere ao trabalho em equipe.

Entende-se a farmácia comunitária no Brasil como sendo um recurso de grande importância para a saúde pública do país, sendo imprescindível que a equipe seja composta unicamente por profissionais Farmacêuticos e Técnicos em Farmácia devidamente formados. Estudos como este contribuem para o processo de formulação das políticas públicas, bem como para a formação de recursos humanos especializados.

Como já foi dito, a atuação do Técnico em Farmácia qualifica as ações em saúde, contribuindo para a garantia da integralidade das/nas ações, e, nesse sentido, a Prática Farmacêutica e Técnica na área deve ser transformada (STEPHANELLI, 2015; BARROS NETO; CYSNEIROS; BORGES, 2018).

Segundo os novos marcos legais, a farmácia não é mais entendida como puramente um ambiente de cunho comercial, mas é, para todos os efeitos legais, um Estabelecimento de Saúde (BRASIL, 2014). Portanto, parece-nos plausível sustentar a tese de que todos que ali estão deveriam minimante possuir educação formal - refiro-me 
à Formação Técnica de Nível Médio em Farmácia - para ofertar um cuidado em saúde adequado. No entanto, por não poderem se inscrever nos Conselhos de Farmácia em quadros separados como técnicos, diante da oferta do curso, muitos desistem de ingressar e, aqueles que já atuam na área, acabam não se qualificando. Os poucos que iniciam o curso e o concluem comumente judicializam a questão. Portanto, entende-se que esforços devem ser empreendidos no sentido de modificar o entendimento da legislação vigente, considerando a lógica da saúde e do interesse público.

Como já foi dito, embora exista a oferta (mesmo que exígua), poucos demonstram interesse, pois a profissão de Técnico em Farmácia não possui recepção e direcionamento legal, visto que se encontra em um campo enredado de interesses, poder, disputas e resistências por parte dos profissionais Farmacêuticos e Conselhos de Farmácia.

Diferentemente dos graduados em Farmácia, os indivíduos que, diante da oferta, ingressam no Curso Técnico de Nível Médio em Farmácia, ao concluírem e receberem o grau, não podem se inscrever nos CRF's, porque a profissão ainda não foi legalmente reconhecida, embora conste no Catálogo Nacional de Cursos Técnicos, do Ministério da Educação (BRASIL, 2009a). O segmento farmacêutico, na prática, não exige educação formal e desconsidera a formação de nível técnico ao remunerar esses funcionários, sendo comum receberem valores iguais aos leigos (sem educação formal específica).

Considerando que a conjuntura possivelmente repercute sobre a demanda (interesse e busca pela qualificação), oferta (de cursos), inserção no mercado de trabalho e nas relações de trabalho, este estudo tem como objetivo se debruçar sobre as trajetórias formativas dos egressos dos Cursos Técnicos de Nível Médio em Farmácia, com o intuito de identificar possíveis elementos que possam contribuir para a EPT e para área Técnica em Farmácia.

\section{REVISÃO DA LITERATURA}

\subsection{Do auxiliar/aprendiz ao Técnico em Farmácia: o caminho das artes farmacêuticas na hostória do Brasil}


Ao atentarmos para os caminhos percorridos pelas artes farmacêuticas no Brasil no decurso da história, é possível compreender e apontar, em certa medida, as possíveis conjunturas que culminaram na divisão do trabalho na área da farmácia sob a égide do grau de formação (STEPHANELLI, 2015).

Logo nos primeiros anos do século XIX, no Brasil, o que hoje conhecemos por farmacêutico recebia o nome de boticário; do mesmo modo, as farmácias eram conhecidas como boticas. Nas boticas, os medicamentos eram produzidos/manipulados artesanalmente e comercializados conforme a demanda. Nesse período, a relação entre cliente/paciente e boticário/farmacêutico era profícua e adornada por um forte vínculo de amizade e confiança, parte disso fruto de um contexto em que o país não dispunha de tantas boticas/farmácias, sendo comum a existência de apenas um estabelecimento farmacêutico por cidade (STEPHANELLI, 2015).

As artes farmacêuticas, aqui entendidas como sendo as técnicas e os conhecimentos referentes às atividades e aos serviços desenvolvidos no âmbito das boticas/farmácias, eram repassadas - transmitidas pelo "mestre" aos demais "aprendizes" - aos auxiliares/funcionários que se interessavam em aprendê-las para praticá-las, pois ainda não havia, no país, instituições formadoras para o ofício em Farmácia, situação que forçava o governo a conceder permissão para abertura de boticas a leigos, tempo também marcado pela inexistência de fiscalizações regulares e procedimentos farmacopeicos padronizados (SANTOS, 1999; VELLOSO, 2007).

Ainda no período que compreende o Brasil Colônia (1530 a 1822), de modo assistemático e tímido deu se início à “formação" (dos) boticária (os), mas ainda, como supramencionado, aprendia-se nas próprias boticas com aqueles que detinham certa experiência na área. No entanto, após esse processo de imersão, devia-se realizar os exames aplicados pela Fiscatura-mor ${ }^{1}$ para comprovar as habilidades e as competências requeridas sobre a Pharmacopêa Geral para o Reino e Domínios de Portugal (STEPHANELLI, 2015). Havendo aprovação no exame, o postulante deveria comprovar o exercício prático de, no mínimo, quatro anos em uma botica de responsabilidade de um boticário legalizado pelo mesmo trâmite regulamentar.

\footnotetext{
${ }^{1}$ [...] era o órgão responsável pela fiscalização do exercício das artes de curar e pela concessão de cartas de físicos, boticários, médicos práticos e curandeiros do Reino, sendo representado pelos cargos de Físico-mor, escrivão-secretário, juízes-comissários-delegados, escrivão, meirinho e visitadorexaminadores da arte farmacêutica (VELLOSO, 2007, p. 26).
} 
Satisfazendo tais requisitos, o delegado da Fiscatura-mor conferia ao requerente o título régio da Carta de Farmácia do Boticário (EDLER, 2006; VELLOSO, 2007).

No início do segundo vintênio do século XIX, extinguiu-se a Fiscatura-mor e a Câmara Municipal foi revestida de autoridade para proceder com as inspeções públicas sanitárias, por intermédio de seus inspetores de saúde que, no caso especial das boticas, aferiam e examinavam a qualidade e o estado das drogas; a organização e a higiene; os preços aplicados (EDLER, 2006; VELLOSO, 2007).

Ainda nesse período, a Carta Régia, publicada em 3 de outubro de 1832 por Dom Pedro II, determinou a "Reforma do Ensino Médico", o que finalmente permitiu a criação e a incorporação do curso de Farmácia em duas Faculdades de Medicina, sediadas nas cidades da Bahia e do Rio de Janeiro. Logo, para obter o título de "pharmaceutico", o postulante deveria cursar e ser aprovado (em um período de três anos) nas disciplinas do curso superior de Pharmacia e, concomitantemente ou não, ter três anos de prática em uma botica/pharmacia de um boticário legalizado (BRASIL, 1832).

Pouco depois, em 1839, foi criada, na cidade mineira de Ouro Preto, a primeira Faculdade de Farmácia do Brasil, independente do curso de Medicina. Nos anos seguintes, com a criação de entidades de classe ${ }^{2}$, iniciou-se uma maior preocupação em torno da melhoria da qualidade do ensino "pharmaceutico" e do combate ao exercício ilegal da profissão (VELLOSO, 2007).

A demora em torno da institucionalização e regulamentação da profisssão "pharmaceutica" e da expansão do ensino "pharmaceutico" no país cooperou para o funcionamento de inúmeras boticas sem a presença desse profissional (VELLOSO, 2007; STEPHANELLI, 2015).

Os anos em que a farmácia brasileira ficou entregue unicamente a indivíduos sem a devida educação formal descontruiu a identidade do Farmacêutico. Muitos "não farmacêuticos" - auxiliares e proprietários - articularam-se e conseguiram autorizações para exercerem a responsabilidade técnica dos estabelecimentos. Os anos passaram e proprietários começaram a ser denominados práticos em Farmácia, oficiais em Farmácia e provisionados em Farmácia, conjuntura que enredou de fronteiras - divisões - às atividades laborais em Farmácia, gerando muita insatisfação por parte dos

\footnotetext{
${ }^{2}$ Sociedade Farmacêutica Brasileira (1851) e o Instituto Farmacêutico do Rio de Janeiro (1858) (VELLOSO, 2007).
} 
Farmacêuticos. Todo esse descontentamento resultou na criação do Conselho Federal de Farmácia (CFF), por força da Lei $n^{\circ}$ 3.820, de 11 de novembro de 1960 (BRASIL, 1960; STEPHANELLI, 2015).

\begin{abstract}
Art. $1^{\circ}$ - Ficam criados os Conselhos Federal e Regionais de Farmácia, dotados de personalidade jurídica de direito público, autonomia administrativa e financeira, destinados a zelar pela fiel observância dos princípios da ética e da disciplina da classe dos que exercem atividades profissionais farmacêuticas no País (BRASIL, 1960, on-line).
\end{abstract}

Ao restabelecer, em seu Art. $33^{3}$, critérios para o processo de licenciamento de oficiais e práticos, essa peça legal forçou o fim da possibilidade de indivíduos, sem a devida educação formal, tornarem-se responsáveis técnicos (BRASIL, 1960).

Já a inscrição em quadros distintos para os auxiliares que possuíam formação técnica - educação formal técnica de nível médio - é facultada, conforme o que está expresso no art. 14, parágrafo único, apenas para

[...] a) os profissionais que, embora não farmacêuticos, exerçam sua atividade (quando a lei autorize) como responsáveis ou auxiliares técnicos de laboratórios industriais farmacêuticos, laboratórios de análises clínicas e laboratórios de controle e pesquisas relativas a alimentos, drogas, tóxicos e medicamentos; b) os práticos ou oficiais de Farmácia licenciados (BRASIL, 1960, on-line).

Portanto, diante da redação do art. 14, os Técnicos em Farmácia, mesmo possuindo educação formal, não detêm o direito de inscrição como profissional de nível de formação distinta do Farmacêutico (BRASIL, 1960; STEPHANELLI, 2015).

Pouco depois, com o "Movimento de 1964" e a ascensão dos militares ao poder, o Brasil vivenciava um período de marcantes mudanças em seu modelo econômico fruto do "milagre econômico" -, decorrentes do alavancado processo de industrialização. Com a produção em larga escala de medicamentos pela indústria farmacêutica brasileira, o mercado demandava a fortiori mão de obra qualificada (BRASIL, 1970; STEPHANELLI, 2015).

\footnotetext{
${ }^{3}$ [...] oficiais de Farmácia, já habilitados na forma da lei, poderão ser provisionados para assumirem a responsabilidade técnico-profissional para farmácia de sua propriedade, desde que, na data da vigência desta lei, os respectivos certificados de habilitação tenham sido expedidos há mais de 6 (seis) anos pelo Serviço Nacional de Fiscalização da Medicina ou pelas repartições sanitárias competentes dos Estados e Territórios, e sua condição de proprietários de farmácia datada de mais de 10 (dez) anos, sendo-lhes, porém, vedado o exercício das mais atividades privativas da profissão de farmacêutico (BRASIL, 1960).
} 
Ciente disso, o presidente da República Emílio Garrastazu Médici sancionou a "Reforma do Ensino de $1^{\circ}$ e $2^{\circ}$ graus" por intermédio da Lei de Diretrizes e Bases da Educação Nacional (Lei $\mathrm{n}^{\circ}$ 5.692), de 1971, que instituiu o ensino profissionalizante obrigatório nas instituições públicas de ensino.

Destarte, ao viabilizar o processo de escolarização e a criação sistematizada dos cursos técnicos de nível médio, contribuiu-se para a criação de inúmeros cursos técnicos de nível médio em saúde, entre os quais o Curso de Nível Médio em Técnico em Farmácia.

\begin{abstract}
Neste contexto, no que diz respeito ao Curso Técnico de Farmácia, o período de formação demandava quatro anos, contemplando ainda a obrigatoriedade de 500 horas de estágio supervisionado em estabelecimentos farmacêuticos. O curso oferecia uma habilitação parcial em Auxiliar de Farmácia e, ao concluírem com aprovação o terceiro ano, os alunos recebiam o certificado de conclusão do $2^{\circ}$ grau. Porém, para receber o diploma de Técnico de Farmácia, era indispensável conclusão do quarto ano (STEPHANELLI, 2015, p. 66).
\end{abstract}

Ainda nos anos de chumbo do "Movimento de 1964", o embalo do contexto brasileiro de expansão industrial também culminou na elaboração da Lei no 5.991, que foi sancionada no dia 17 de dezembro de 1973 pelo mesmo presidente. A Lei em questão definiu as atividades e os estabelecimentos farmacêuticos como comércio e deu outras providências. Embora tenha sido a primeira legislação sanitária brasileira direcionada ao comércio de medicamentos, devemos ter a clareza de reconhecer o seu caráter autoritário e mercantilista, ao passo que define os estabelecimentos farmacêuticos como comércios voltados unicamente ao lucro, bem como também possibilita a abertura por leigos $^{4}$ desde que cumpridas as exigências quanto à responsabilidade técnica. No entanto, convenhamos que, em 1970, existiam poucos cursos de Farmácia no Brasil (BRASIL, 1973; BARROS NETO, 2017).

Além disso, mal redigida ao utilizar o termo "técnico responsável", essa legislação não é suficientemente clara quanto à obrigatoriedade do profissional Farmacêutico (bacharel em farmácia inscrito no CRF) como o único elegível à responsabilidade técnica nos estabelecimentos farmacêuticos, vício que dá margem para

\footnotetext{
${ }^{4}$ Art. 57 - Os práticos e oficiais de farmácia, habilitados na forma da lei, que estiverem em plena atividade e provarem manter a propriedade ou co-propriedade de farmácia em 11 de novembro de 1960, serão provisionados pelo Conselho Federal e Conselhos Regionais de Farmácia para assumir a responsabilidade técnica do estabelecimento (BRASIL, 1973).

${ }^{5}$ Art. 15 - A farmácia e a drogaria terão, obrigatoriamente, a assistência de técnico responsável, inscrito no Conselho Regional de Farmácia, na forma da lei.
} 
decisões jurídicas ineptas desfavoráveis quanto a essa imprescindibilidade (BRASIL, 1973; CORRER; OTUKI, 2013).

Portanto, por permitir uma interpretação equivocada (quando lida ao pé da letra), a lei em questão caminhou na contramão do que se pretendia com a "Reforma do Ensino de $1^{\circ}$ e $2^{\circ}$ graus", porque impulsionou uma nova onda de indivíduos sem educação formal, acrescida também por técnicos, a reivindicarem para si a responsabilidade técnica, uma vez que existia uma provável dificuldade enfrentada pelos proprietários para encontrar farmacêuticos formados que atendessem às exigências da Lei $n^{\circ} 3.820 / 60$, pois o número de faculdades que ofertavam o curso de Farmácia era exíguo naquele período (STEPHANELLI, 2015).

O imbróglio culminou em inúmeras ações judiciais. No entanto, até o momento (fev. 2019), todas as ações movidas foram indeferidas pelo Poder Judiciário (PERINI, 2003; GONÇALVES, 2017), sobretudo, após a vigência da Lei $n^{\circ} 13.021$, de 8 de agosto de 2014, que estabeleceu que:

Art. $5^{\circ}$ - No âmbito da assistência farmacêutica, as farmácias de qualquer natureza requerem, obrigatoriamente, para seu funcionamento, a responsabilidade e a assistência técnica de farmacêutico habilitado na forma da lei (BRASIL, 2014, on-line).

No presente, o ensino técnico em saúde no Brasil possui um caráter privado quando comparamos a distribuição com o setor público. Em 2011, em levantamento realizado na base de dados do Cadastro Nacional de Cursos de Educação Profissional de Nível Técnico (Instituto Nacional de Pesquisas Educacionais Anísio Teixeira), do total de cursos cadastrados (2.991) “[...] no país, 11,94\% eram do setor público e $88,06 \%$, do setor privado" (PRONKO et al., 2011, p. 107). Ainda nesse estudo, foi observado que havia o cadastro de 124 (4,15\%) cursos de habilitação na subárea Farmácia. Quanto à distribuição segundo dependência administrativa, 2,80\% eram públicos e 4,33\%, privados. Por região, a distribuição foi $1,61 \%$ no Norte; 7,26\%, Nordeste; 79,84\%, Sudeste; $8,87 \%$, Sul e 2,42\%, Centro-Oeste (PRONKO et al., 2011). No entanto, por inúmeras razões, entre as quais a expressiva e contínua expansão da rede EPT, há de se considerar que, possivelmente, ocorreram mudanças nessas distribuições.

Assim sendo, diante do que foi apresentado, percebe-se a necessidade de uma legislação, que seja mais consistente e alinhada à atual política pública de saúde 
brasileira, regulamentando a inscrição desses profissionais técnicos em quadros distintos, para a efetiva qualificação da assistência farmacêutica no país.

\subsection{A Educação profissional técnica em Farmácia}

A expansão da Educação Profissional e Tecnológica (EPT) culminou na oferta e na criação de inúmeros cursos, entre os quais o Curso de Nível Médio em Técnico em Farmácia. Essa conjuntura tem contribuído para a capacitação profissional para a atuação no segmento farmacêutico em especial, para a dispensação do medicamento (BEZZEGH; GOLDENBERG, 2011; GRECO, 2009; STEPHANELLI, 2015).

À luz das palavras do Ministério da Educação (MEC), por intermédio do Catálogo Nacional de Cursos Técnicos (CNCT), o Técnico em Farmácia é o profissional de Farmácia de nível médio que

\footnotetext{
[...] realiza operações farmacotécnicas. Identifica e classifica produtos e formas farmacêuticas, composição e técnica de preparação. Manipula formas farmacêuticas alopáticas, fitoterápicas, homeopáticas e de cosméticos. Realiza testes de controle da qualidade. Executa, como auxiliar, as rotinas de compra, armazenamento e dispensação de produtos. Realiza o controle e manutenção do estoque de produtos e matérias-primas farmacêuticas, sob supervisão do Farmacêutico. Atende as prescrições médicas dos medicamentos e identifica as diversas vias de administração. Orienta sobre o uso correto e a conservação dos medicamentos (BRASIL, 2016, p. 23).
}

No entanto, majoritariamente a farmácia - assistência farmacêutica - no Brasil, está entregue a leigos, indivíduos sem a mínima educação formal; balconistas e "práticos" que possuem condutas questionáveis do ponto de vista técnico, científico e ético (CORRER; OTUKI, 2013).

A farmácia comunitária é, antes de tudo, um estabelecimento de saúde. Sua principal função é a dispensação de medicamentos que possuem um caráter dual, pois, dependendo da forma como é usado, pode ocasionar efeito positivo ou negativo no paciente (BASTOS; COSTA; CASTRO, 2011). Diante disso, é indiscutível que a oferta de um serviço de qualidade é primordial para a promoção do uso racional de medicamentos (CORRER, OTUKI, 2013).

Não obstante, o Conselho Federal de Farmácia (CFF), de maneira arbitrária, guiado por interesses de classe, ignora a existência dos demais profissionais (com e sem 
educação formal de nível técnico - recursos humanos) que trabalham nas farmácias comunitárias, pois não define uma padronização do quantitativo desses trabalhadores, restringindo a inscrição, a fiscalização e a defesa apenas da classe farmacêutica.

Essa situação se torna ainda mais complexa se atentarmos para o fato de que o curso Técnico em Farmácia no Brasil tem sua execução regulamentada pelo MEC e consta no Catálogo Nacional de Cursos Técnicos (CNCT), indo além ao ter a profissão - ocupação "Técnico em Farmácia" - recepcionada pelo Ministério do Trabalho e Emprego (MTE) por meio da Classificação Brasileira de Ocupações (CBO) (BRASIL, 2016; BRASIL, 2019).

Tal desinteresse por parte do CFF denuncia certo distanciamento condenável da discussão em torno da importância da formação profissional técnica em saúde dos trabalhadores de nível médio inseridos nos serviços de saúde no Brasil, com precária qualificação e reconhecimento profissional, pauta que vem sendo discutida desde o movimento da Reforma Sanitária Brasileira, cujos desdobramentos estão presentes no texto da Carta Política Pátria do Brasil (PRONKO et al., 2011).

Felizmente, mesmo existindo desinteresse, desdém e inércia por parte do CFF, encontra-se no Poder Legislativo, na Câmara dos Deputados, tramitando em caráter conclusivo, o Projeto de Lei $\mathrm{n}^{\circ}$ 668/2011, que visa regulamentar o exercício da profissão do Técnico em Farmácia (BRASIL, 2018).

À vista disso, muitos pesquisadores têm defendido que, em diferentes atividades na farmácia, o Farmacêutico carece do auxílio de outros profissionais e a atuação do técnico devidamente habilitado (com educação formal especifica) qualifica a Prática Farmacêutica (MARIN et al., 2003; CORRER, OTUKI, 2013; STEPHANELLI, 2015). Portanto, ao invés de contratar profissionais que não possuem formação formal, os estabelecimentos farmacêuticos, ao compor o seu quantitativo de recursos humanos, deveriam contratar o Técnico em Farmácia.

A esse respeito, salientamos que o referido curso, para conferir o perfil profissional com as competências e as habilidades supramencionadas, deve possuir carga horária mínima de $1200 \mathrm{~h}$ e ter, em seus componentes curriculares, estágios e disciplinas básicas e específicas como anatomia, fisiologia, biologia, química, farmacologia e legislação farmacêutica, entre outras, com aulas teóricas e práticas em laboratórios para que o egresso de fato disponha de habilidades e competências 
indispensáveis para atuar nos diversos segmentos da área farmacêutica, executando as atividades pertinentes sob a supervisão do Farmacêutico (PEREIRA, 2009; BRASIL, 2016). Ademais, cito para que fique claro, que o campo de atuação do Técnico em Farmácia no Brasil incluí:

[...] drogarias. Unidades básicas de saúde e Unidades de dispensação do SUS. Farmácias de manipulação. Farmácias homeopáticas. Indústria farmacêutica. Indústria de cosméticos. Farmácias hospitalares. Distribuidoras de medicamentos, insumos e correlatos (BRASIL, 2016, p. 23).

Nos Estados Unidos da América (EUA), nas farmácias do país, apenas o profissional que obteve formação formal em Técnico em Farmácia (Pharmacy Tecnican) é habilitado para o trabalho, sob a supervisão do Farmacêutico. O referido curso também comtempla disciplinas básicas e específicas como no Brasil (JOHNSTON et al., 2009).

No Brasil, em razão do não reconhecimento da profissão técnica por parte do CFF, não é comum encontrar esses profissionais atuando no segmento farmacêutico, pois resta pouco incentivo para permanecer no segmento farmacêutico para aqueles que buscaram se qualificar obtendo educação formal. É uma situação muito diferente da dos EUA, onde apenas o Farmacêutico e o profissional Técnico em Farmácia podem atuar no segmento farmacêutico após certificação em órgão competente (GONÇALVES, 2017). Sobre isso, ao invés de se oporem, os Farmacêuticos e o CFF, em respeito à farmácia, deveriam reconhecer que não há mais espaço para improvisações e atuações amadorísticas na farmácia brasileira (GRECO, 2009).

Nessa linha, mencionamos o que foi evidenciado em estudo conduzido por Gonçalves (2017), em que se observou, após aplicação de um teste, que o indivíduo com educação formal no curso Técnico em Farmácia, cuja duração em média é de 18 meses (um ano e meio), possui um conhecimento notoriamente maior que os balconistas (sem educação formal), os quais possuem em média 10 a 18 anos de experiência. Logo, a aplicação do teste demonstrou que os balconistas precisam de muitíssimo tempo de experiência para obter um conhecimento muito inferior ao dos Técnicos em Farmácia, que, por sua vez, é obtido em um ano e meio. Portanto, fica evidente a importância de se investir na educação formal desses profissionais, bem como limitar a atuação de profissionais sem tal formação. 
A partir dessas informações, resta claro que a educação formal é essencial e deveria ser requisito fundamental para atuação de todos os profissionais que queiram atuar nos diversos segmentos da área farmacêutica, cabendo ao CFF contribuir para a legalização da atuação dos técnicos, bem como fiscalizar e exigir tais requisitos e não ser pedra de tropeço para o avanço do Projeto de Lei supradito.

\section{MÉTODO}

Este foi um estudo de campo descritivo de desenho - natureza qualitativa on-line (por intermédio da internet), com entrevistas assíncronas, realizadas por questionário semiestruturado (APÊNDICE A) para obtenção dos dados (CAMILLO, 2017). Em observância aos objetivos, buscamos debruçar nossa investigação sobre a narrativa da biografia - história de vida dos participantes -, sendo esse o nosso tipo de estudo.

Durante as entrevistas com os participantes, pedimos que eles narrassem suas experiências - trajetórias formativas - cronologicamente, de maneira geral e, de modo específico, sobre alguns aspectos. Portanto, no decurso das entrevistas, foi solicitado aos participantes que fizessem uma reflexão retrospectiva acerca de suas vivências e experiências sobre um determinado tema ou aspecto (ou vários), como também narrassem de modo que se ativessem às vivências, aos significados, aos sentimentos e às emoções que tinham percebido e vivido em cada experiência ao longo de sua trajetória formativa. Pediu-se, além disso, a inclusão de uma análise pessoal sobre os resultados, as consequências etc. das situações criadas após as experiências narradas (SAMPIERI; COLLADO; LUCIO, 2015).

Por meio desse método, foi possível acessar as trajetórias formativas de cada participante, permitindo uma análise profunda e holística (como um "todo") das partes de interesse, o que possibilitou a descrição, o entendimento e a compreensão do contexto de cada fato vivenciado e narrado, considerando o passado e o que restou dele (resultados: sequelas e desdobramento atual da história). As histórias de vida foram contadas pelo participante, mas a estruturação e a narração final foram elaboradas em um segundo momento pelo pesquisador que conduziu a pesquisa (SAMPIERI; COLLADO; LUCIO, 2015). 
Os dados coletados foram examinados com o método de análise de conteúdo de Bardin (2011) e estão apresentados a seguir na seção RESULTADOS deste texto.

\subsection{Sujeitos da Pesquisa}

Por conveniência, para compor a amostra foram feitas buscas por currículos cadastrados na Plataforma Lattes. Para tanto, utilizamos os descritores "Técnico em Farmácia" e "Técnico de Farmácia". Entramos em contato por e-mail com 10

indivíduos que tinham declarado, em seu Currículo lattes, ter frequentado o Curso Técnico de Nível Médio em Farmácia. Na mensagem enviada, esclarecemos o que se tratava o estudo, bem como os nossos propósitos por meio dele; por fim, convidava-os para participarem do estudo. Desse total, cinco retornaram e aceitaram participar da pesquisa. Foram-lhes enviadas, por e-mail, as duas vias do Termo de Consentimento Livre e Esclarecido (TCLE) que, após leitura e esclarecimento de eventuais dúvidas e questionamentos, assinaram, ficando de posse de uma das vias. Após assentimento, em nova mensagem foi enviado a cada participante o questionário semiestruturado. Por fim, a identificação dos participantes se deu por codificação alfanumérica e sequencial (Técnico (a) em Farmácia 1...).

\section{RESULTADOS E DISCUSSÃO}

Primeiramente, será apresentado, de modo resumido, o perfil dos participantes do presente estudo e, nas seções seguintes, os demais resultados analisados e discutidos, sob a égide do cumprimento das questões alicerçantes da investigação. 


\subsection{O perfil dos participantes}

Tabela 1 - Perfil dos participantes do estudo

\begin{tabular}{|c|c|c|c|c|c|c|c|}
\hline Participante & Sexo & $\begin{array}{l}\text { Idade } \\
\text { (anos) }\end{array}$ & $\begin{array}{l}\text { Tempo } \\
\text { de } \\
\text { formado } \\
\text { (a) } \\
\text { (anos) }\end{array}$ & Instituição & $\begin{array}{l}\text { Verticalização } \\
\text { Segunda } \\
\text { Graduação }\end{array}$ & Instituição & $\begin{array}{l}\text { Stricto } \\
\text { Sensu } \\
\text { Mestrado }\end{array}$ \\
\hline TF. 1 & $\pi$ & 27 & 2 & Privada & $1^{*}$ & Privada & - \\
\hline TF. 2 & q & 22 & 5 & Privada & 1 & Privada & - \\
\hline TF. 3 & $\hat{0}$ & 25 & 8 & Pública & 1 & Privada & - \\
\hline TF. 4 & q & 28 & 8 & Pública & 1 & Pública & $1^{*}$ \\
\hline TF. 5 & $\hat{0}$ & 23 & 3 & Privada & $1^{*}$ & Privada & - \\
\hline
\end{tabular}

Fonte: Elaboração do autor (2019).

Notas: TF. $=$ Técnico $(\mathrm{a})$ em Farmácia

$q=$ Feminino

$\hat{\jmath}=$ Masculino

* Em andamento

Vê-se que três participantes são do sexo masculino e dois do sexo feminino. Em relação à faixa etária, possuem entre 22 e 28 anos. A maioria é de egressos de instituições particulares (3/2), apenas dois são egressos de instituições públicas. Possuem entre dois e oito anos de formados no curso de nível técnico. Todos que concluíram o curso de nível técnico optaram pela verticalização para cursos de graduação no próprio itinerário formativo, prevalecendo o curso de bacharelado em Farmácia (4/5), apenas uma participante optou pela verticalização para o curso de graduação em bacharelado em Engenharia Civil (1/5) (BRASIL, 2016). Três concluíram o curso de graduação (dois em bacharelado em Farmácia e uma em Engenharia Civil) e dois são graduandos. Uma das participantes - Técnica em Farmácia e Farmacêutica - é mestranda (pós-graduação stricto sensu).

Ante o exposto, observa-se que não é dada importância à formação continuada em cursos de especialização técnica no itinerário formativo, mas é dada grande importância na verticalização para os cursos de graduação próprios do itinerário formativo. Essa conjuntura será melhor compreendida nas próximas seções. 


\title{
4.2 Trajetórias formativas e suas contribuições
}

\subsubsection{A escolha pelo curso Técnico em Farmácia}

A escolha profissional está adornada de inúmeros fatores singulares sociais, abarcando influências do meio familiar, da formação educacional, destarte do contexto social, político, econômico e cultural. Portanto, embora a trajetória de vida seja influenciada e influencie cada um desses fatores, é sua totalidade que conduz à decisão (POLYDORO; PRIMI, 2003) que, por sua vez, requer autoconhecimento.

Os discursos dessa categoria versam sobre o percurso que conduziu a escolha pelo Curso de Nível Médio em Técnico em Farmácia e os elementos que foram significativos para a escolha profissional: a afinidade, a experiência, o incentivo familiar, a vocação e as incertezas.

\begin{abstract}
Decidi ingressar no curso, pois comecei a trabalhar como jovem aprendiz numa indústria farmacêutica, como ainda não tinha escolhido uma graduação para fazer e tinha gostado muito da área, decidi começar pelo curso técnico pois teria uma menor duração e caso eu não gostasse/me identificasse, seria mais vantajoso desistir ali do que numa graduação e caso eu gostasse, seguiria em frente. Portanto, optei pelo curso para ter certeza na hora de decidir pela área e seguir estudando pensando em vagas com uma melhor remuneração, além de criar uma base de conhecimento para ser usada na faculdade (Técnico em Farmácia 5).

$\mathrm{Na}$ época minha irmã era farmacêutica, fui fazer o técnico para ver se me identificava, pois não queria fazer faculdade no primeiro momento. Para mim foi uma boa experiência, pude ter uma noção do que era e definir e decidir por outra área (Técnica em Farmácia 1).
\end{abstract}

Vê-se, nesses discursos, que parte dos participantes optaram, de modo planejado, pelo curso técnico, em razão da possibilidade de experimentar e conhecer com mais afinco a área de atuação, antes de decidir por um curso de graduação de nível superior que, em comparação, possui maior duração e custo.

Situação um tanto diferente dos demais entrevistados, cujas respostas demonstraram que a opção pelo curso não foi uma trajetória profissional planejada, em razão da pouca idade, associada à insuficiência de referências e informações.

Quando escolhi o curso não sabia o que almejava profissionalmente. Escolhi apenas porque gostava de laboratório e sabia que neste curso eu poderia conhecer mais esta área (Técnica em Farmácia 2). 
Não houve motivo específico para a escolha. Eu era muito jovem, tinha quinze anos e não sabia muito bem o que eu queria (Técnica em Farmácia 4).

Nesses discursos, observa-se que, no plano individual, a escolha profissional assume uma extraordinária importância, pois vindica uma definição consciente do que se pretende vivenciar no futuro e, em meio a esse processo complexo de decisão, emergem as incertezas, sobretudo quando se é estudante de ensino médio (PRIMI et al., 2000). Logo, as narrativas, evidenciam que há, na escolha, uma certa intencionalidade, impregnada por razões objetivas e subjetivas.

\subsubsection{O curso e a inserção no mercado de trabalho}

No decurso do curso Técnico em Farmácia, o discente tem contato com inúmeras disciplinas teóricas e práticas e estágios obrigatórios (PEREIRA, 2009). Parte dos participantes mencionaram que o curso demandou dedicação e apoio familiar em razão da complexidade do conteúdo.

[...] o curso exigiu muita dedicação e estudos todos os dias (Técnica em Farmácia 4).

[...] tive dificuldade com algumas matérias, mas não foi impedimento para não finalizar o curso, porque tive muito apoio da minha irmã que é farmacêutica (Técnica em Farmácia 1).

A trajetória escolar e profissional dos jovens requer dedicação e apoio daqueles que compõem o seu entorno social (CINTRA, 2014). Os discursos dessa classe evidenciam a escolha pelo ensino técnico como possibilidade de inserção no mundo adulto, tanto pela verticalização - prosseguimento dos estudos no ensino superior como pelo ingresso no mercado de trabalho formal.

O início do curso me mostrou que essa seria a área que eu iria escolher para sempre. Me formei em 2014, e só consegui atuar como Técnica de Farmácia em 2017. Um bom período após a minha formação. Minha primeira experiência no segmento farmacêutico foi como auxiliar de Farmácia (Técnica em Farmácia 2).

Hoje vejo que o curso técnico é útil para quem pretende cursar o nível bacharel, pois auxilia nos estudos e se torna um diferencial na conquista de estágios melhores (Técnico em Farmácia 3). 
Vê-se, também, nas falas anteriores que, para o profissional Técnico em Farmácia, há certa dificuldade no ingresso no mercado de trabalho devido às barreiras colocadas pela falta de recepcionamento legal. Portanto, não é comum oferta de vagas com a exigência da formação, bem como com a denominação em questão, como é claro nos discursos a seguir.

\begin{abstract}
Até hoje, mais de dois anos formado, nunca consegui trabalhar como Técnico de Farmácia, faltam oportunidades, a maioria das vagas é apenas para auxiliar de Farmácia ou para estagiários. Após o término do contrato com a indústria, fiquei desempregado por aproximadamente seis meses, até ingressar na farmácia de alto custo em que trabalho atualmente (Técnico em Farmácia 5).

[...] assim que finalizei o curso consegui trabalhar apenas como auxiliar de Farmácia, onde fiquei por anos, e depois fui atuar em uma drogaria na área administrativa (Técnica em Farmácia 1).

Não tive dificuldades com a entrada no mercado de trabalho, pois realizei concurso público, porém o curso é pouco conhecido, e por isso não há muitos concursos voltados para essa formação, o que acaba dificultando a inserção desses profissionais (Técnica em Farmácia 4).
\end{abstract}

Nessa categoria, encontram-se também discursos em que os participantes fazem um balanço sobre a matriz curricular do curso e pontuam o que deveria ser aprimorado para formar profissionais com competências e habilidades em consonância com as funções que desempenharão no segmento farmacêutico, qualificando o acesso e a permanência no mercado de trabalho. Em suas falas, os participantes frisaram a importância de um maior enfoque no ensino teórico e prático de deontologia e legislação farmacêutica brasileira.

O curso deveria ter um foco maior em áreas regulatórias e do setor de qualidade (Técnico nem Farmácia 3).

É um curso muito amplo e completo, cobre consideravelmente toda a área das ciências farmacêuticas a que se destina. No entanto, um dos principais empregadores desses profissionais são hospitais e serviços hospitalares. Então aulas relacionadas a esse campo podem ser ainda mais enfatizadas (Técnica em Farmácia 4).

[...] na minha formação, senti falta da parte legislativa, portarias e resoluções, vejo que alguns colegas têm a dificuldade de explicar o motivo de uma receita de psicotrópico ter validade de trinta dias, por exemplo. Assim como senti falta da abordagem das nossas atribuições, tudo ainda é muito focado na drogaria, no balcão (Técnico em Farmácia 5).

A disciplina de deontologia e legislação farmacêutica é de uma importância impar para a vivência e a prática profissional; entretanto, por vezes, esse reconhecimento só ocorre quando o indivíduo adentra no mercado de trabalho. Uma solução pedagógica é trabalhá-la de modo inter, multi e transdisciplinar em outras 
disciplinas, visando à transversalidade desse componente curricular, para que o discente perceba a sua importância nas diferentes áreas de atuação do Técnico em Farmácia (MARINI; FERREIRA, 2014; MELO et al., 2017).

\subsubsection{A educação formal é tão importante quanto o recepcionamento legal}

Quando se analisam os discursos característicos dessa terceira e última categoria, vê-se que as falas estão relacionadas ao contexto político do não recepcionamento e direcionamento legal da profissão técnica em Farmácia, bem como os seus desdobramentos que enredam o campo: desvalorização, falta de empregabilidade, conflitos, interesses, disputas e resistências.

[...] O curso é bom, porém nos entristece por não ter nenhum reconhecimento por parte do Conselho Federal de Farmácia, isso desanima as turmas. [...] e muitos chegam a desistir do curso (Técnica em Farmácia 1, grifo nosso).

Incomoda pois não faz sentido ter o curso e não ser reconhecido (Técnico em Farmácia 3, grifo nosso).

É extremamente frustrante, uma vez que em farmácias e drogarias, mesmo em hospitais muitas vezes não há nem a necessidade de ter a formação que nós, Técnicos em Farmácia tivemos, acredito que seja até um fator desestimulante para futuros profissionais que gostariam de ingressar na área [...] não somos reconhecidos apesar de todo o nosso conhecimento, mas se nós lutarmos por nossos direitos, podemos colocar as situações ao nosso favor (Técnico em Farmácia 5, grifos nossos).

O contexto político em questão aqui aparece sob dois aspectos entrelaçados: a desvalorização da profissão e a postura fraterna, pautada na integralidade do cuidado como resistência que conduz a valorização mesmo frente a realidade:

Quando atuei como estagiário, notei que por ter mais conhecimento técnico por conta do curso técnico, obtive mais confiança e respeito dos colegas das demais áreas da saúde (Técnico em Farmácia 3).

Estou sempre em contato com os demais profissionais para eliminar problemas, encontrando soluções para a realização dos procedimentos visando à promoção da saúde e à humanização do atendimento ao paciente. [...] eu visualizo os demais profissionais como uma grande equipe, não como profissionais trabalhando individualmente, e isso faz com que o principal beneficiado seja o paciente (Técnico em Farmácia 5).

Eu tinha uma participação muito ativa e lidava diretamente com o público [...]. Sou realizada por ter tido o privilégio em ter atuado e sido reconhecida, o que infelizmente não acontece com todos (Técnica em Farmácia 1). 
Os avanços na área farmacêutica e nas políticas públicas de saúde têm exigido a qualificação da assistência farmacêutica. Nesse sentido, os participantes frisaram a importância do trabalho do Técnico em Farmácia na assistência direta com o paciente, sob a supervisão do Farmacêutico como parte que deveria ser vista como indissociável desse processo.

\begin{abstract}
Há uma necessidade crescente por profissionais que possuam qualificação técnica de nível médio para auxiliar o Farmacêutico, devido ao aumento das atribuições do mesmo (Técnica em Farmácia 4).

Nós somos o profissional, abaixo do Farmacêutico, mais entendido sobre medicamentos, temos uma visão ampla da área e somos peça importante nesse segmento. Precisamos estar presentes para prestar a assistência direta ao paciente, quando eu consigo efetivamente prestá-la e proporcionar ao paciente o acesso a uma informação que ele não tem e contribuir para o sucesso do seu tratamento, é o que me motiva continuar. Por isso nunca pensei em deixar a profissão, tenho esperança de que dias melhores virão (Técnico em Farmácia 5).
\end{abstract}

A formação e a incorporação do Técnico em Farmácia estão imersas em um contexto histórico de oposição concebida por um comportamento corporativista por parte dos Farmacêuticos. Nessa esteira, mencionam também as razões que os levaram à verticalização para curso de graduação em Farmácia que pertence ao itinerário formativo: vocação, ruptura dos fatores limitantes e maior reconhecimento.

Gosto muito desta área, não me imagino trabalhando com outra coisa; este é o que me motiva|: continuar atuando (Técnica em Farmácia 2).

No serviço público, o Técnico em Farmácia é reconhecido e respeitado e por isso a carreira se torna interessante. Porém, pensando no futuro, concluir a Faculdade de Farmácia (Técnica em Farmácia 4).

O curso me motivou a fazer a graduação, apesar de todos os poréns da área, realmente senti como uma vocação e não me enxergo ingressando em outra área (Técnico em Farmácia 5).

O que se pretende não é a equiparação dos direitos e das atribuições do Técnico em Farmácia com os do Farmacêutico, mas a proteção e o direcionamento legal específico quanto às atribuições que são pertinentes ao nível técnico, porque o profissional Técnico em Farmácia possui especificidades em seus processos de trabalho - em suas ações construídas no cuidado em saúde -; é portador de potencialidades que devem ser reconhecidas pelo profissional Farmacêutico que objetiva a qualificação da assistência farmacêutica.

Essa é a expectativa de todos os discentes, docentes e egressos dos cursos Técnicos em Farmácia, como também de alguns poucos Farmacêuticos, na medida em 
que se saber possuidor de direitos é, para o ser humano, algo inestimável e de imenso valor (GONÇALVES FILHO, 1998).

\section{CONSIDERAÇÕES FINAIS}

Os sonhos possíveis precisam de luta para se tornarem realidade. O direito nos dá o instrumento para que, por meio de constante luta, alimentada pela esperança, alcancemos o que sonhamos.

A legalização da profissão Técnica em Farmácia é uma deliberação oportuna e urgente, que exigirá a formação institucional para atuação após inscrição nos Conselhos de Farmácia, pois coopera assim para consolidação e expansão dos Cursos Técnicos de Nível Médio em Farmácia, com a EPT, bem como para a inclusão do pessoal Técnico em Farmácia no segmento farmacêutico e, em especial, na Atenção Básica. Ao qualificar o processo de trabalho Farmacêutico e Técnico, bem como a assistência farmacêutica, tal legalização otimiza tempo e recursos, aumentando a produtividade e a resolutividade das ações na farmácia; ressignificando os espaços sociais, tanto no âmbito público quanto no privado. No entanto, é importante que ambos os profissionais - o Técnico e o Farmacêutico - estejam abertos para o trabalho em equipe, integrado e articulado, compartilhando saberes e práticas, como preza o princípio da integralidade.

Os resultados apresentados fornecem subsídios que contribuem para proposição de políticas direcionadas tanto à EPT quanto ao reconhecimento profissional. Reconhecemos as políticas públicas como um instrumento que operacionaliza as reformas necessárias nas instituições públicas e nas organizações em geral (DIAS; MATOS, 2012). A proposta de uma política pública voltada para a questão deve basearse em ampla análise das potencialidades da educação formal e reconhecimento legal para a qualificação da assistência farmacêutica no Brasil. Portanto, uma política dessa natureza deve ser articulada e condicionada pelas dimensões: econômica, social e educacional. Atrelados a essas dimensões, os objetivos devem se propor: 1) buscar o desenvolvimento econômico e social, por meio da definição, da proteção e do direcionamento legal especifico quanto às atribuições pertinentes ao nível técnico, respeitando as especificidades dos processos de trabalho desse profissional, consequentemente, permitindo a sua inscrição e sua incorporação em quadro separados 
nos Conselhos Regionais de Farmácia, bem como exigir a educação formal e o número de inscrição para atuação no mercado de trabalho; 2) diminuir a desigualdade social e facilitar o acesso equitativo ao ensino Técnico em Farmácia; 3) propor, após ampla discussão cívica e democrática, novas Diretrizes Curriculares Nacionais para o curso Técnico em Farmácia, redefinindo os princípios, os fundamentos, as condições e os procedimentos para a formação em nível Técnico em Farmácia, para serem aplicadas, em âmbito nacional, na organização, no desenvolvimento e na avaliação dos projetos pedagógicos do curso em questão, tendo em vista os avanços no campo da deontologia e legislação farmacêutica brasileira; 4) conceber a política pública em questão de forma integrada, sob a ótica dos princípios de universalidade, de cooperação, de integralidade e, sobretudo, de eficácia e eficiência, conferindo equilíbrio político, social e econômico; 5) promover, sob a ótica da saúde, em especial do princípio da integralidade, condições para sensibilização e estabelecimento de vínculos entre os profissionais Técnicos em Farmácia e Farmacêuticos, rompendo disputas históricas e reconhecendo a necessidade de mudança, como via para promoção de um interesse comum: a qualificação da assistência farmacêutica no Brasil.

Nesse sentido, com fundamentos nas lições de Dias e Matos (2012), reconhecemos que o problema público, apresentado neste estudo, por violar compromissos legítimos; por enfraquecer a condição comum desses determinados profissionais; por ir contra os valores alicerçantes das políticas de saúde do país e pelos danos causados aos bens sociais, incide na necessidade de uma política pública que, orientada pelas dimensões e pelos objetivos antes mencionados, resolva todo o problema social e público em questão.

Evidentemente, este estudo possui certas limitações, que podem ser superadas por estudos futuros, especialmente no que se refere ao tamanho da amostra. A Farmácia no Brasil reclama mudança, porque mudança é da vida. Compete ao legislativo e ao CFF reconhecê-las e fazê-las com serenidade, segurança e, principalmente, respeito à Carta Política Pátria do Brasil.

\section{REFERÊNCIAS}

BARDIN, Laurence. Análise de conteúdo. São Paulo: Edições 70, 2011. 
BARROS NETO, Sebastião Gonçalves de; CYSNEIROS, Roberta Monterazzo; BORGES, Luiz Henrique. Percepção do Farmacêutico sobre sua relação de trabalho com o Técnico em Farmácia: Integralidade no Cuidado a Saúde. In: CONGRESSO DE EDUCAÇÃO PROFISSIONAL E TECNOLÓGICA DO IFSP, 4., 2018, Araraquara. Anais... Araraquara: IFSP, 2018. p. 1-4.

BARROS NETO, Sebastião Gonçalves de. O cuidado farmacêutico no âmbito da atenção básica sob a ótica da integralidade. 2017. 168 f. Dissertação (Mestrado em Políticas Públicas e Desenvolvimento Local) - Escola Superior de Ciências da Santa Casa de Misericórdia de Vitória, Vitória, 2017.

BASTOS, Augusto Amorim; COSTA, Ediná Alves; CASTRO, Lia Lusitana Cardozo de. Trabalho em saúde: vigilância sanitária de farmácias no município de Salvador (Bahia, Brasil). Ciência \& Saúde Coletiva, Rio de Janeiro, v. 16, n. 5, p. 2397-400, 2011.

BEZZEGH, Nadine Judith; GOLDENBERG, Paulete. The challenge of responsible dispensing: formal education versus professional practice. Brazilian Journal of Pharmaceutical Sciences, v. 47, n. 1, p. 63-3, 2011.

BRASIL. Câmara dos Deputados. PL 668/2011. Regulamenta o exercício da profissão do Auxiliar de Farmácias e Drogarias. Disponível em:

$<$ http://www.camara.gov.br/proposicoesWeb/fichadetramitacao?idProposicao=4943 $>$ Ac esso em: 11 jul. 2018.

BRASIL. Lei de 3 de outubro de 1832. Dá nova organização ás actuaes Academias Medico-cirurgicas das cidades do Rio de Janeiro, e Bahia. Disponível em: <http://www2.camara.leg.br/legin/fed/lei_sn/1824-1899/lei-37274-3-outubro-1832563716-publicacaooriginal-87775-pl.html>. Acesso: 20 out. 2018.

BRASIL. Lei $n^{\circ}$ 5.648, de 11 de dezembro de 1970. Cria o Instituto Nacional da Propriedade Industrial e dá outras providências. Diário Oficial da União, 1970. Disponível em: 〈http://www.planalto.gov.br/ccivil_03/leis/L5648.htm>. Acesso em: 20 out. 2018.

BRASIL. Lei n ${ }^{\circ} 13.021$, de 8 de agosto de 2014. Dispõe sobre o exercício e a fiscalização das atividades farmacêuticas. Diário Oficial da União, Brasília, 11 ago. 2014. Disponível em: <http://www.planalto.gov.br/ccivil_03/_Ato20112014/2014/Lei/L13021.htm>. Acesso em: 13 out. 2018.

BRASIL. Lei no 5.991, de 17 de dezembro de 1973. Dispõe sobre o Controle Sanitário do Comércio de Drogas, Medicamentos, Insumos Farmacêuticos e Correlatos, e dá outras Providências. Brasília, 1973. Disponível em: <http://www.planalto.gov.br/ccivil_03/LEIS/L5991.htm>. Acesso em: 5 dez. 2018. 
BRASIL. Lei no 3.820, de 11 de novembro de 1960. Cria o Conselho Federal e os Conselhos Regionais de Farmácia e dá outras providências. Diário Oficial da União. Brasília, 1960.

BRASIL. Ministério da Educação. Catálogo Nacional de Cursos Técnicos. Brasília, 2009a.

BRASIL. Ministério da Educação. Catálogo Nacional de Cursos Técnicos. 3. ed. Brasília, 2016.

BRASIL. Ministério da Saúde. Diretrizes para estruturação de farmácias no âmbito do Sistema Único de Saúde. Brasília, 2009b. Disponível em:

<http://www.planalto.gov.br/ccivil_03/leis/L3820.htm >. Acesso em: 7 jun. 2017.

BRASIL. Ministério do Trabalho. Classificação Brasileira de Ocupações

<http://www.mtecbo.gov.br/cbosite/pages/pesquisas/ResultadoOcupacaoMovimentacao .jsf >. Acesso em: 07 de mar. 2019.

CAMILLO, Eliane Juraski. A qualidade "de dentro" na/da pesquisa qualitativa em Educação do Sul do Brasil. Educar em Revista, Curitiba, v. 33, n. 65, p. 137-48, 2017.

CINTRA, Mariana Simões Ferreira. A importância da família, escola e pares no processo de escolha pelo ensino médio técnico. 2014. $121 \mathrm{f}$. Dissertação (Mestrado em Educação) - Universidade de São Paulo, São Paulo, 2014.

CONSELHO FEDERAL DE FARMÁCIA (Brasil). Nota Técnica: perguntas e respostas referentes às Resoluções do CFF n $n^{\circ} 585$ e nº 586, de 29 de agosto de 2013. Brasília, 2013.

CORRAL, Florentina Santos Diez Del; SOUZA, Mirabeau Levi Alves de; NEGRÃO, Odulia Leboreiro. Do boticário ao farmacêutico: o ensino de farmácia na Bahia de 1815 a 1949. Salvador: EDUFBA, 2009.

CORRER, Cassyano Januário; OTUKI, Michel Fleith (Org.). A prática farmacêutica na farmácia comunitária. Porto Alegre: Artmed, 2013.

CORRER, Cassyano Januário; PONTAROLO, Roberto; RIBEIRO, Alyne Simon de Carvalho. A farmácia comunitária no Brasil. In: CORRER, Cassyano Januário; OTUKI, Michel Fleith (Org.). A prática farmacêutica na farmácia comunitária. Porto Alegre: Artmed, 2013. p. 3-26.

DIAS, Reinaldo; MATOS, Fernanda. Políticas públicas: princípios, propósitos e processos. São Paulo: Atlas, 2012.

EDLER, Flavio Coelho. Boticas \& Pharmacias: uma história ilustrada da farmácia no Brasil. Rio de Janeiro: Casa da Palavra, 2006. 
GONÇALVES, Ana Maria Rosa Freato. A importância da educação formal para a dispensação de medicamentos: um estudo transversal. 2017. 177 f. Dissertação (Mestrado em Ciências Farmacêuticas) - Faculdade de Ciências Farmacêuticas, Universidade de São Paulo, Ribeirão Preto, 2017.

GONÇALVES FILHO, José Moura, Humilhação social: um problema político em psicologia. Psicologia USP, São Paulo, v. 9, n. 2, p.11-67, 1998.

GRECO, Maria Cecília Machado. O curso técnico em farmácia na ETSUS-SP: contribuições para o debate. 2009. 137 f. Dissertação (Mestrado Profissional em Gestão do Trabalho e da Educação na Saúde) - Escola Nacional de Saúde Pública Sergio Arouca, Rio de Janeiro, 2009.

JOHNSTON, Mike et al. The pharmacy technician foundations and practies. Upper saddle river: New Jersey, 2009.

MARIN, Nelly et. al (Org.). Assistência farmacêutica para gerentes municipais. Rio de Janeiro: OPAS/OMS, 2003.

MARINI, Danyelle Cristine. FERREIRA, Luis Marcos. Ética voltada para o curso de formação de farmacêuticos. In: BRASIL. Brasil. Conselho Regional de Farmácia do Estado de São Paulo. Ensino de deontologia e legislação farmacêutica: conceitos e práticas. São Paulo: CRFSP, 2014. p. 9-15.

MELO, Daniela Oliveira de et al. Capacitação e intervenções de técnicos de farmácia na dispensação de medicamentos em Atenção Primária à Saúde. Ciência \& Saúde Coletiva, Rio de Janeiro, v. 22, n. 1, p. 261-8, 2017.

MERHY, Emerson Elias. Saúde: a cartografia do trabalho vivo em ato. São Paulo: Editora Hucitec, 2002.

NAVES, Janeth de Oliveira Silva; MERCHAN-HAMANN, Edgar; SILVER, Lynn Dee. Orientação farmacêutica para DST: uma proposta de sistematização. Ciência \& Saúde Coletiva, Rio de Janeiro, v. 10, p. 1005-14, 2005.

PEREIRA, Sandra. Profissão técnico em Farmácia. Revista Poli Saúde educação trabalho, v. 1, n. 5, p. 22-3, maio/jun., 2009.

PERINI. Edson. Assistência farmacêutica: fundamentos teóricos e conceituais. In: ACURCIO, Francisco de Assis. Medicamentos e Assistência Farmacêutica. Belo Horizonte: Coopmed, 2003.

POLYDORO, Soely Aparecida Jorge; PRIMI, Ricardo. Integração ao ensino superior: explorando sua relação com características de personalidade e envolvimento acadêmico. In: MERCURI, Elizabeth (Org.). Estudante Universitário: características e experiências de formação. Taubaté: Cabral Editora e Livraria Universitária, 2003. p. 4166. 
PRIMI, Ricardo et al. Desenvolvimento de um inventário de levantamento das dificuldades da decisão profissional. Psicologia: reflexão e crítica [online], v. 13, n. 3, p.451-63, 2000. Disponível em: <http://dx.doi.org/10.1590/S010279722000000300013 >. Acesso em: 12 dez. 2018.

PRONKO, Marcela et al. A formação de trabalhadores técnicos em saúde no Brasil e no Mercosul. Rio de Janeiro: EPSJV, 2011.

SAMPIERI, Roberto Hernández; COLLADO, Carlos Fernández; LUCIO, María Del Pilar Baptista. Metodologia de pesquisa. São Paulo: MacGrawHill, 2015.

SANTOS, Manoel Roberto da Cruz. Profissão farmacêutica no Brasil: história, ideologia e ensino. Ribeirão Preto: Ed. Holos, 1999.

STEPHANELLI, Lásaro Linhares. Técnicos em farmácia em atividades de assistência farmacêutica na atenção básica à saúde do Sistema Único de Saúde: formas de inserção e participação. 2015. 94 f. Dissertação (Mestrado Profissional em Educação Profissional em Saúde) - Escola Politécnica de Saúde Joaquim Venâncio, Fundação Oswaldo Cruz, Rio de Janeiro, 2015.

VELlOSO, Verônica Pimenta. Farmácia na Corte Imperial (1851 - 1887): práticas e saberes. 2007. 345 f. Tese (Doutorado em História das Ciências em Saúde) - Fundação Oswaldo Cruz, Rio de Janeiro, 2007. 